\title{
GEOGRAPHICAL DISTRIBUTION OF PEDIATRIC CANCER IN ROMANIA
}

DOI: https://doi.org/10.18509/GBP210367n

UDC: 616-006.6-053.2(498.11)

\author{
Iulia Daniela Nedelcu, ${ }^{1,2}$ \\ Adrian Gabriel Simion 1,2 \\ Daniel Peptenatu ${ }^{1,2}$ \\ ${ }^{1}$ University of Bucharest - Faculty of Geography, Bucharest, Romania. \\ ${ }^{2}$ Research Centre for Integrated Analysis and Territorial Management, Bucharest, Romania.
}

\begin{abstract}
Cancer in the young population is less common than in the adult population, however, cancer is one of the leading causes of death among children. Most of the time the cause of the development of cancerous tumors is not known, so prevention is not exactly possible. The survival rate among children increased significantly in Europe and the US until the 1990s (80\%), stagnating after this period, mainly due to the inability of the medical system to make progress in treating cancer.

In Romania, the survival rate in pediatric cancer reaches $69 \%, 10$ percent lower than in Western European countries. For this analysis, a database with national coverage was used, reported at the level of the territorial administrative unit, regarding the types of cancer, for the total cases age category 0-18 years, female and male. This study aims to identify those geographical areas where extreme values have been recorded and to draw premises on the role of the geographical factor in the appearance and development of cancerous tumors among the young population, up to 18 years.
\end{abstract}

Keywords: cancer distribution, spatial modeling, GIS methods

\section{INTRODUCTION}

Cancer is the leading cause of death among young people everywhere, after deaths caused by accidents, with approximately 300,000 new cases diagnosed with cancer in the 0-18 age group each year. The most common types of pediatric cancer are: leukemia, brain and spinal cord tumors, neuroblastoma, lymphoma, bone cancer and rhabdomyosarcoma, they can't be prevented or screened. Although there are child-specific cancers, in rarer cases, they develop adult-specific cancers [1], [2], [3], [4]. Access to the medical system or the existence of a high-performance health system makes a major difference in terms of oncological mortality among children. Over $80 \%$ of pediatric cancers are cured in highincome countries and up to $20 \%$ in many low- and middle-income countries. Therefore, many of the deaths are caused by the lack of an early and accurate diagnosis and the lack of treatment because of financial reasons [5], [6].

A first step towards the effective treatment of as many cases of pediatric cancer as possible, is the implementation of public policies that support low- and middle-income countries, through early diagnosis and the adoption of effective treatment.

In support of these public policies come the Geographic Information Systems that allow the modeling of statistical data to report a simplified situation of this global phenomenon. Most of the time, medical reports are analyzed from a statistical point of view without discussing the spatial component [7], [8]. To do this, the data are spatially modeled, 
geographic information systems can create sets of spatial models in an automated manner, allowing to do specific analysis. Geographic Information Systems are one of the tools used in implementing public policies capable of collecting, storing and processing a huge volume of statistical data with spatial reference [9], [10], [11], [12].

Medical data and the development of related GIS technologies make a significant contribution to research, minimize data processing time, help perform detailed analyzes, and spatially identify carcinogenic concentrations.

\section{RESEARCH METHODOLOGY}

To make this scientific material we used a database provided by the Ministry of Health, with national coverage reported at the level of territorial administrative unit for the period 2008-2017. The number of cancer cases for the 0-18 age group was reported in the total number of people, total, female and male.

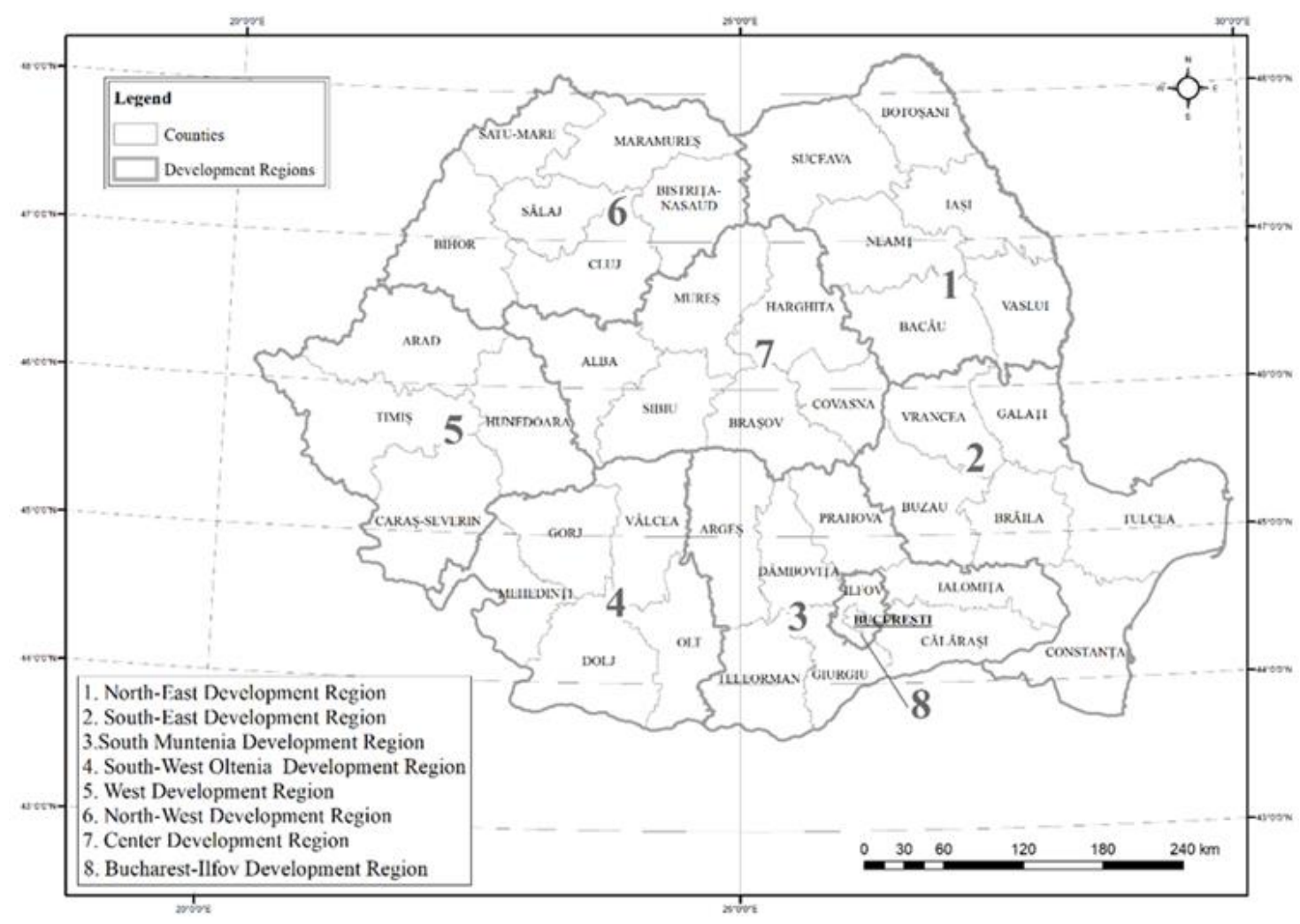

Figure 1. Development regions and counties of Romania

To make the spatial models, several steps were followed, starting with the processing of medical records using a relational database system RDBMS-Postgres SQL, thus generating the database used in this material, a database that allows multiple records. The processing, aggregation and pivoting time depends a lot on the hardware configuration used. Following these steps, the data is exported in tabular form in Microsoft Excel compatible format, so that it can be used later in spatial modeling programs. The data are represented by weight, number of cases of cancer related to the average population. In the last stage, the spatial models are made using the ArcGis software, assigning to each territorial administrative unit the value that corresponds to it. The results are expressed as a percentage and classified into 5 ranges represented in gray tones, high values with light 
tones and low values with dark tones to black. Thus, the pediatric cancer was represented at UAT level for the period 2008-2017.

\section{RESULTS}

In the following figures (from fig. No. 2 to fig. No. 11) was represented the geographical distribution of pediatric cancer for the age group 0-18 years, as a percentage, for the period 2008-2017 in the form of spatial models.

Analyzing the 10 spatial models as well as the database used for these representations, several localities were highlighted, either localities with extreme maximum and minimum values, or localities with negative or positive evolutions.

Therefore, the localities in which maximum values were registered above the last threshold of $10 \%$ in one or more years are: Ulmu locality from Calarasi county registers in 2008 a value of $33.41 \%$ o, $20.86 \%$ in 2009 , having a downward trend, reaching 3.82 $\%$ in the last year analyzed. Svinita locality from Mehedinti county registers $12.88 \%$ in $2008,12.04 \%$ in 2009 , following the same evolution as of the previously mentioned locality, reaching $0 \%$ in 2017. Another locality with values above the last threshold is Bunesti locality from Brasov county which registers $12,78 \%$ in 2008, $7.28 \%$ in 2010, decreasing to $0.73 \%$ in 2017. Mihailesti locality from Giurgiu county registers a percentage of $11.49 \%$ in 2008, 1, $06 \%$ in 2014 and $0.26 \%$ in 2017.

Another category of localities that attracts our attention is the one where the first years analyzed recorded an incidence of $0 \%$, having an accentuated evolution from one year to another. The locality of Boianu Mare from Bihor county registers an incidence of $0 \%$ in the first three years analyzed, reaching $29.66 \%$ in 2017, with a constant evolution after the 3 years without cancer cases. Recea-Cristur locality from Cluj county registers 0 incidence in the years 2008, 2009, 2012, 2014 and 2015, with a maximum in 2017, 12.28 $\%$. Another locality highlighted is Buesti from Ialomita county with $0 \%$ incidence in 9 consecutive years and $10.75 \%$ incidence in 2017. In Sacel locality from Harghita county a similar phenomenon happens, values from the first threshold or $0 \%$ incidence are maintained, reaching maximum in 2017, $9.59 \%$.

What we can observe both from the cartographic representations and from the statistical database is the fact that the evolution of the incident is not exactly ascending or descending, it shows sudden fluctuations, increases or decreases either with isolated locations or specific areas with the same features. 


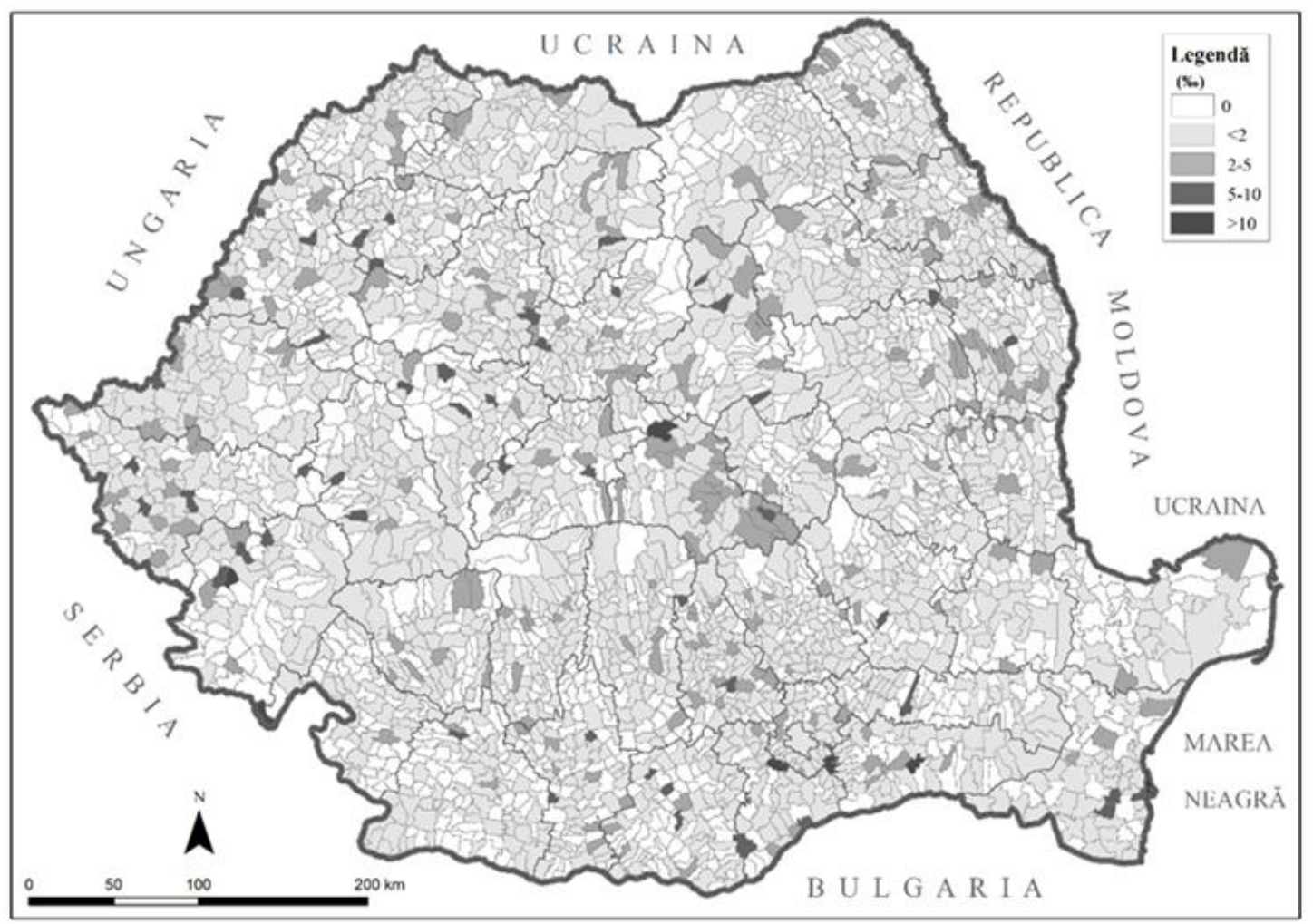

Figure 2. Geographical distribution of pediatric cancer -total (\%) year 2008. Source: Ministry of Health

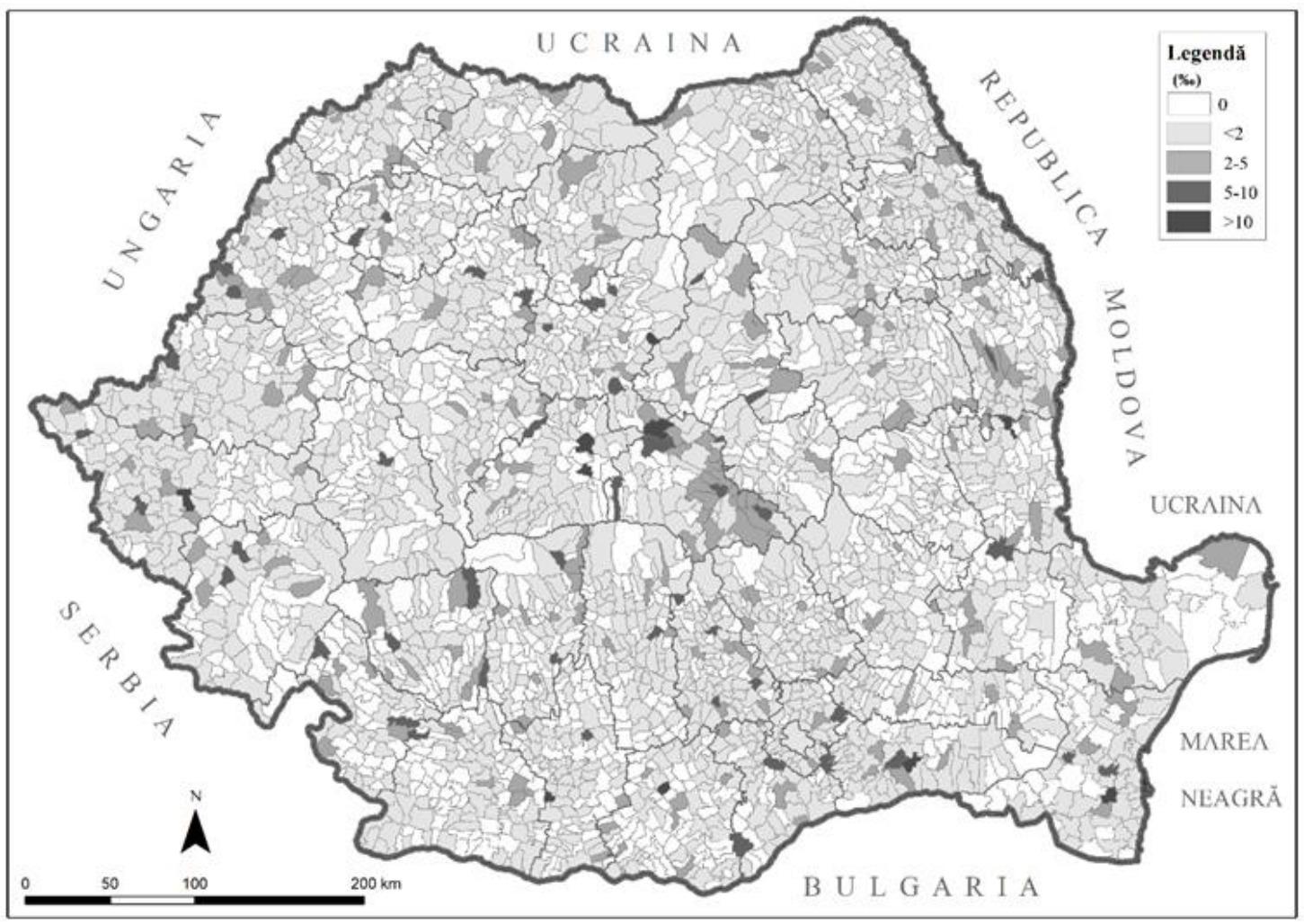

Figure 3. Geographical distribution of pediatric cancer - total (\%) year 2009. Source: Ministry of Health 


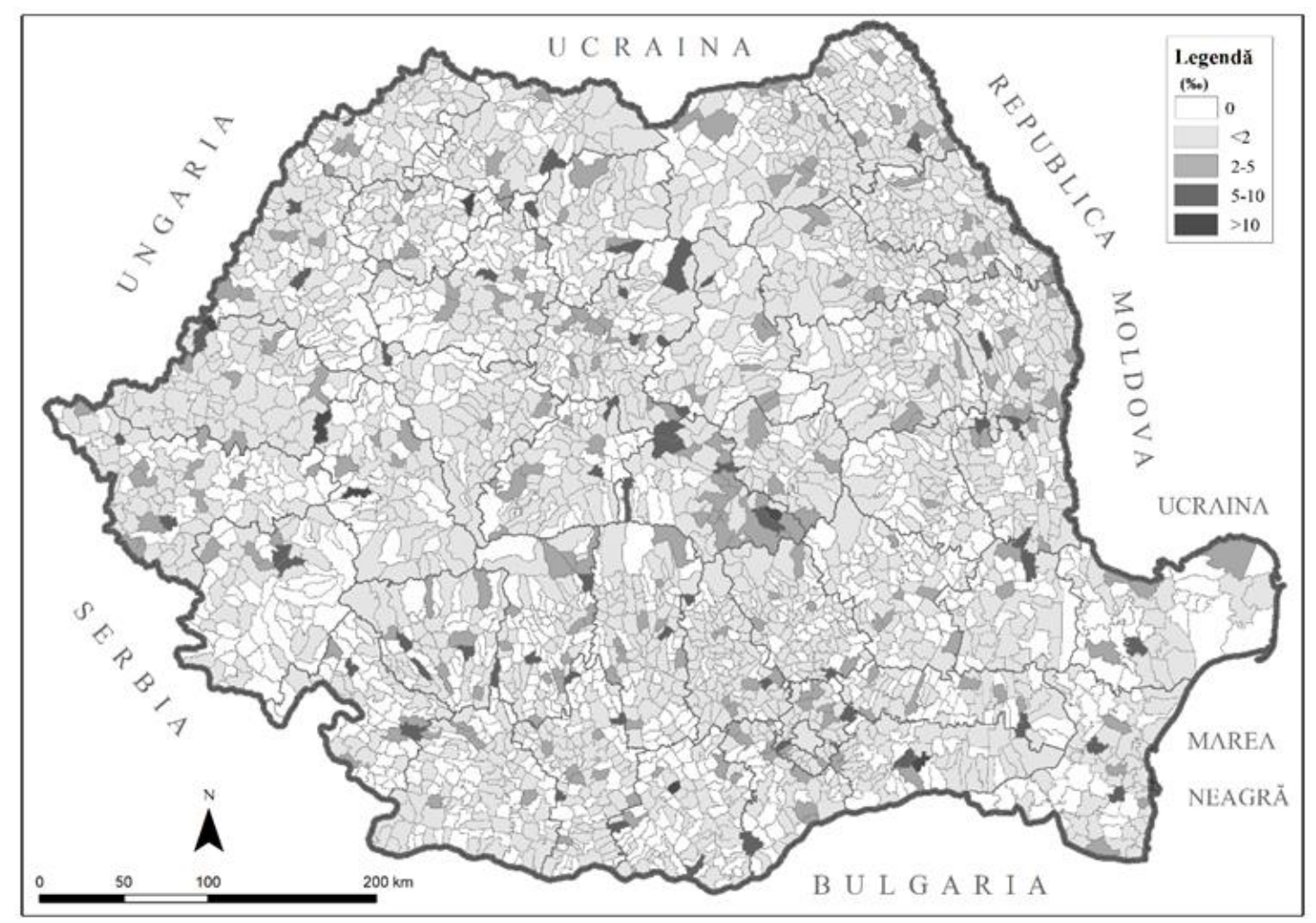

Figure 4. Geographical distribution of pediatric cancer -total (\%o) year 2010. Source: Ministry of Health

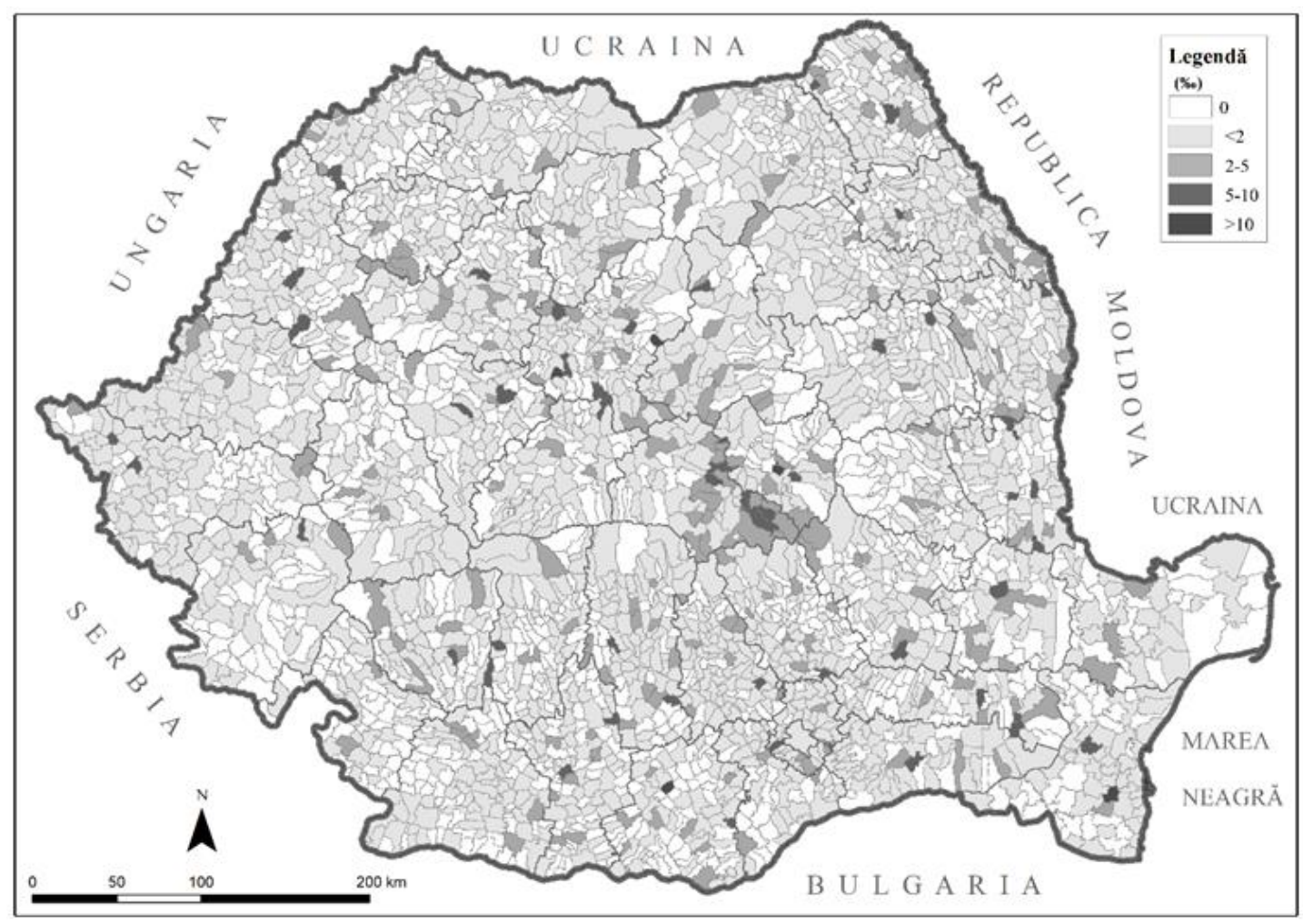

Figure 5. Geographical distribution of pediatric cancer -total (\%o) year 2011. Source: Ministry of Health 


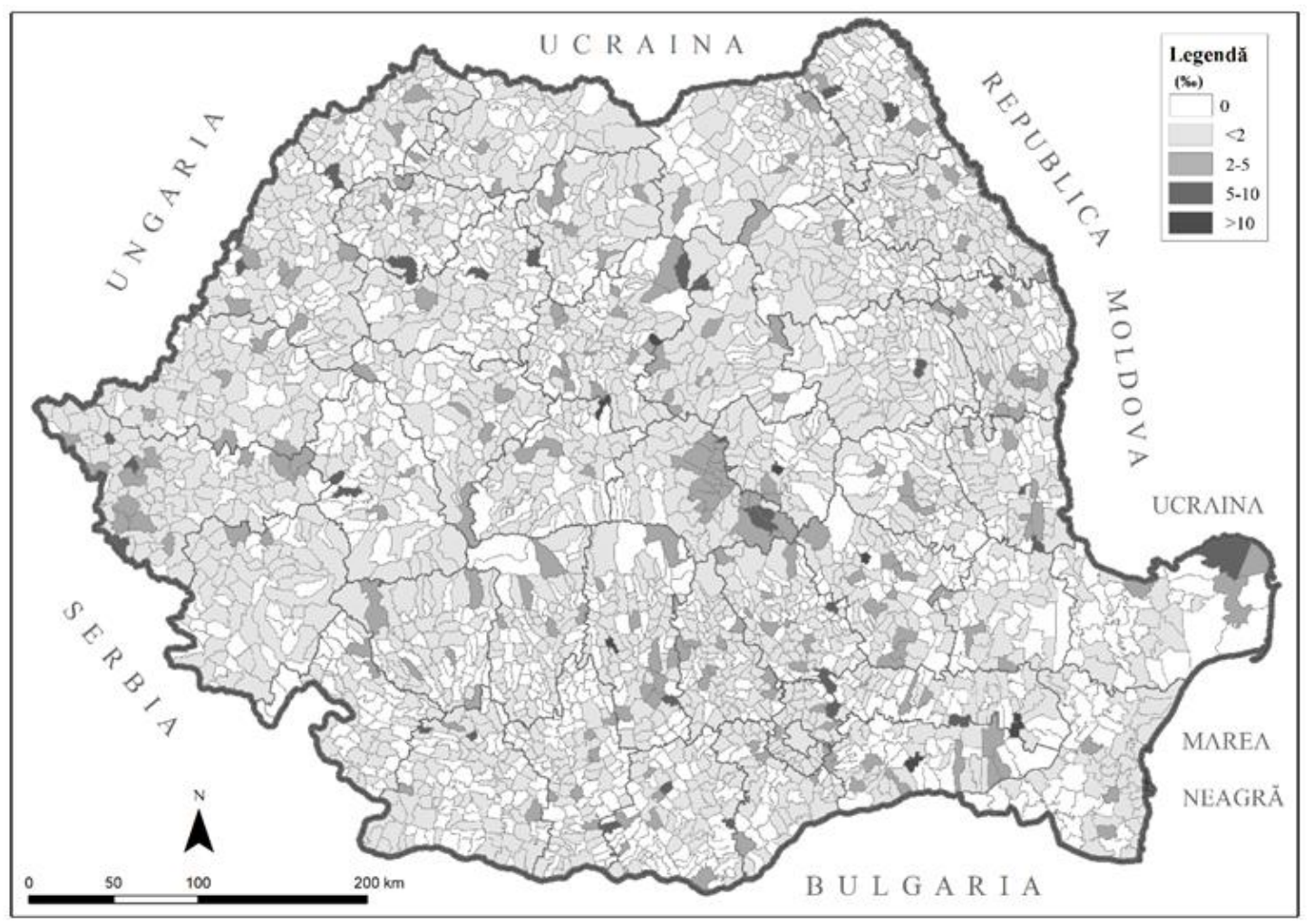

Figure 6. Geographical distribution of pediatric cancer -total (\%) year 2012. Source: Ministry of Health

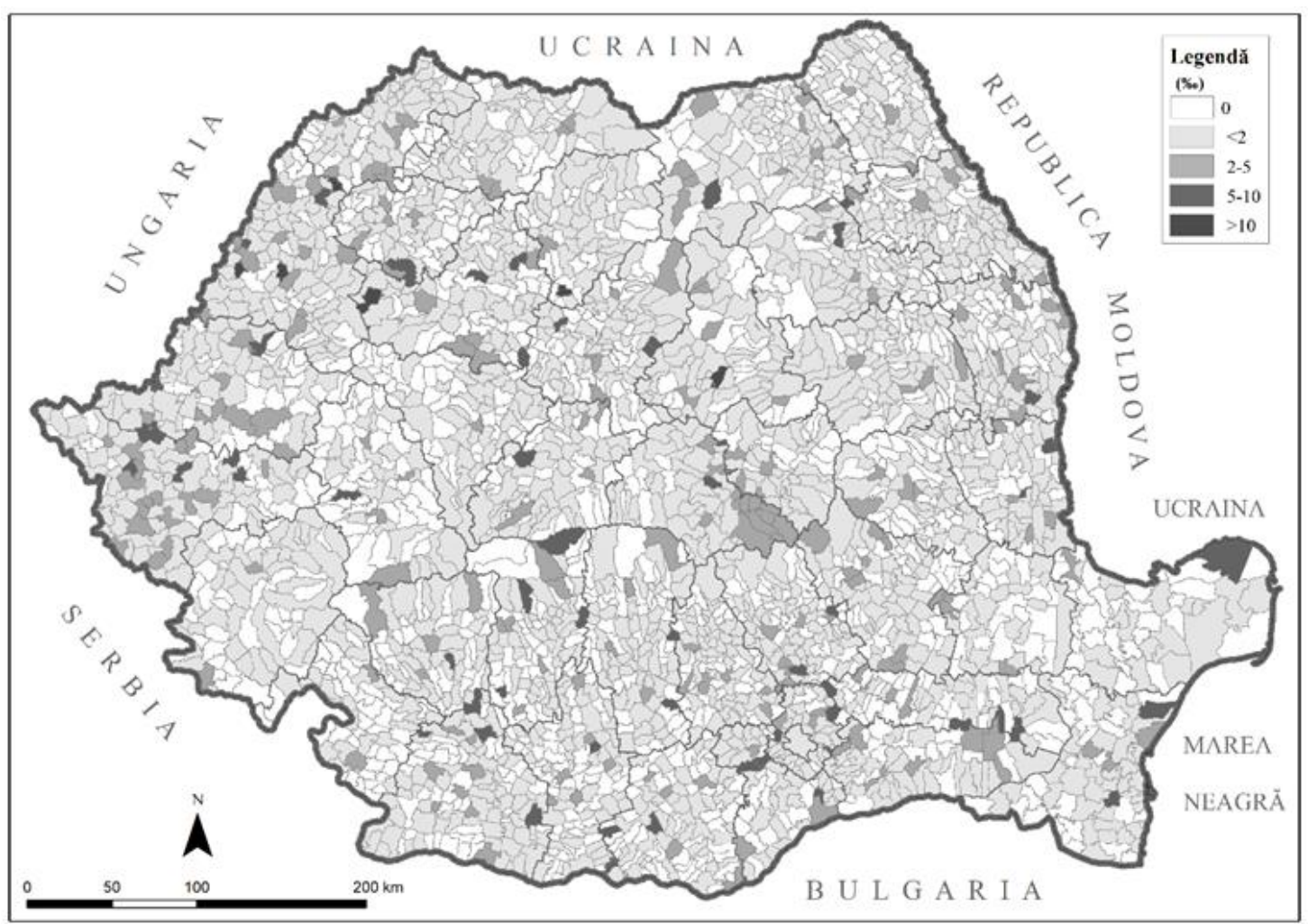

Figure 7. Geographical distribution of pediatric cancer -total (\%) year 2013. Source: Ministry of Health 


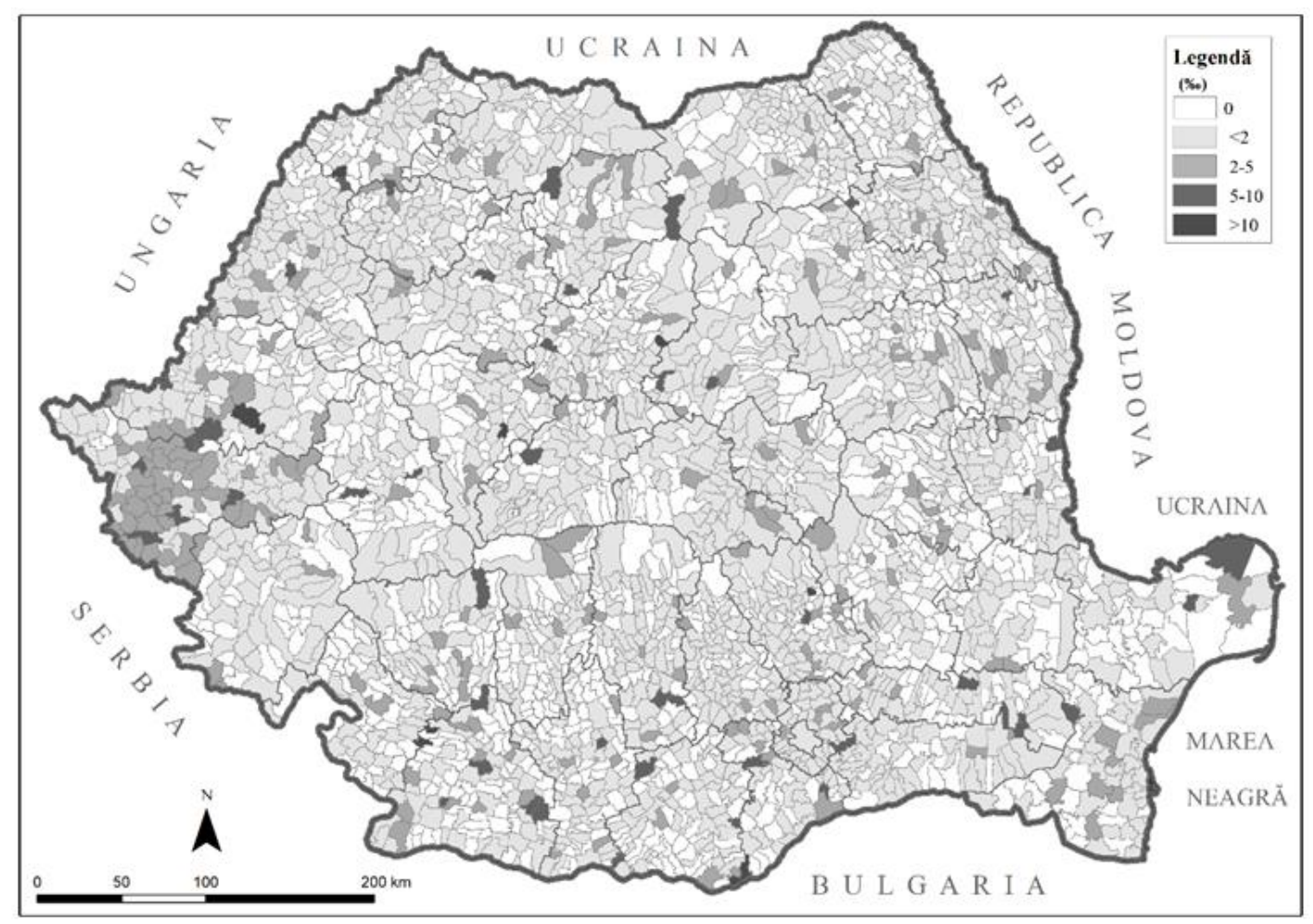

Figure 8. Geographical distribution of pediatric cancer -total (\%) year 2014. Source: Ministry of Health

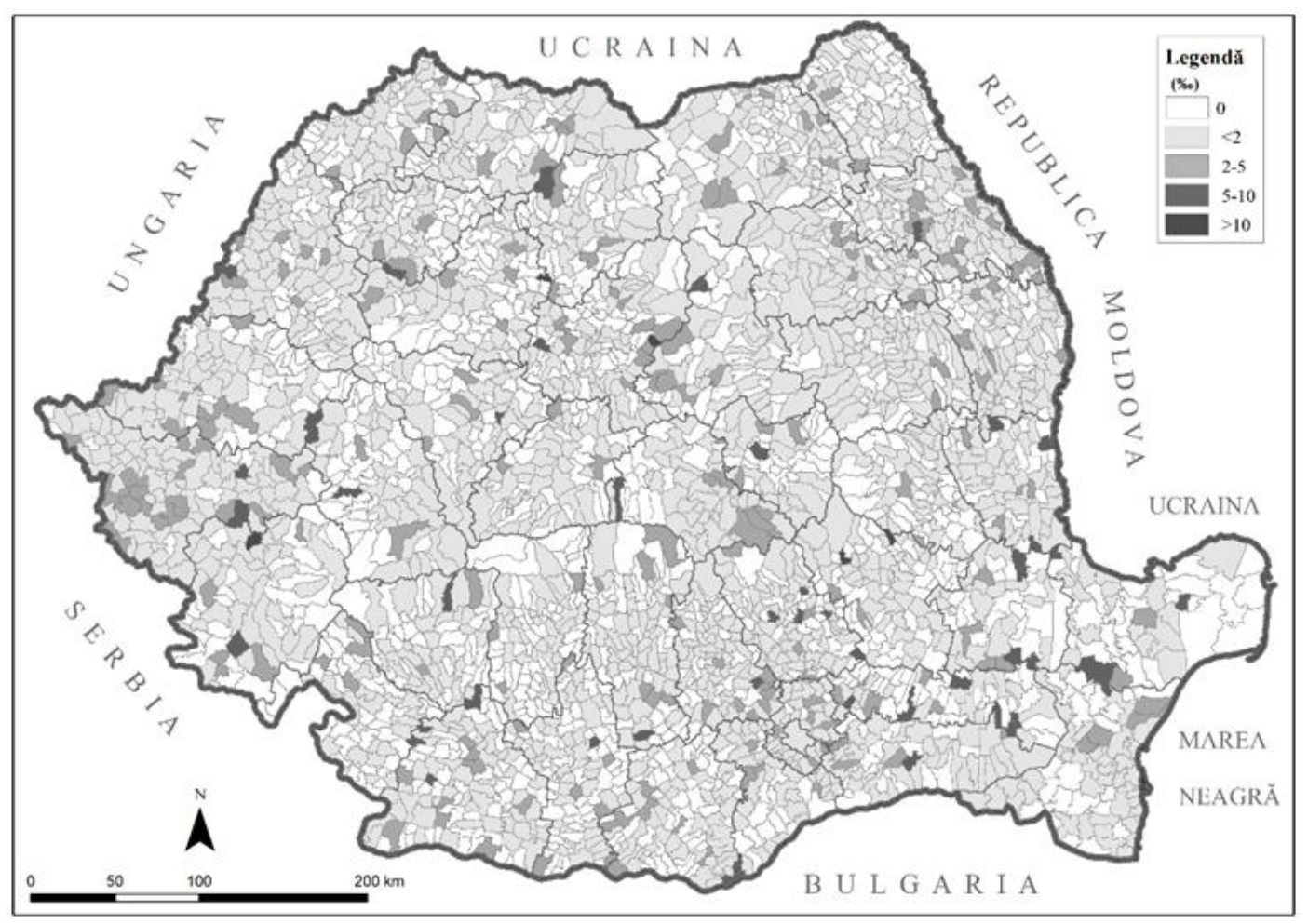

Figure 9. Geographical distribution of pediatric cancer -total (\%) year 2015. Source: Ministry of Health 


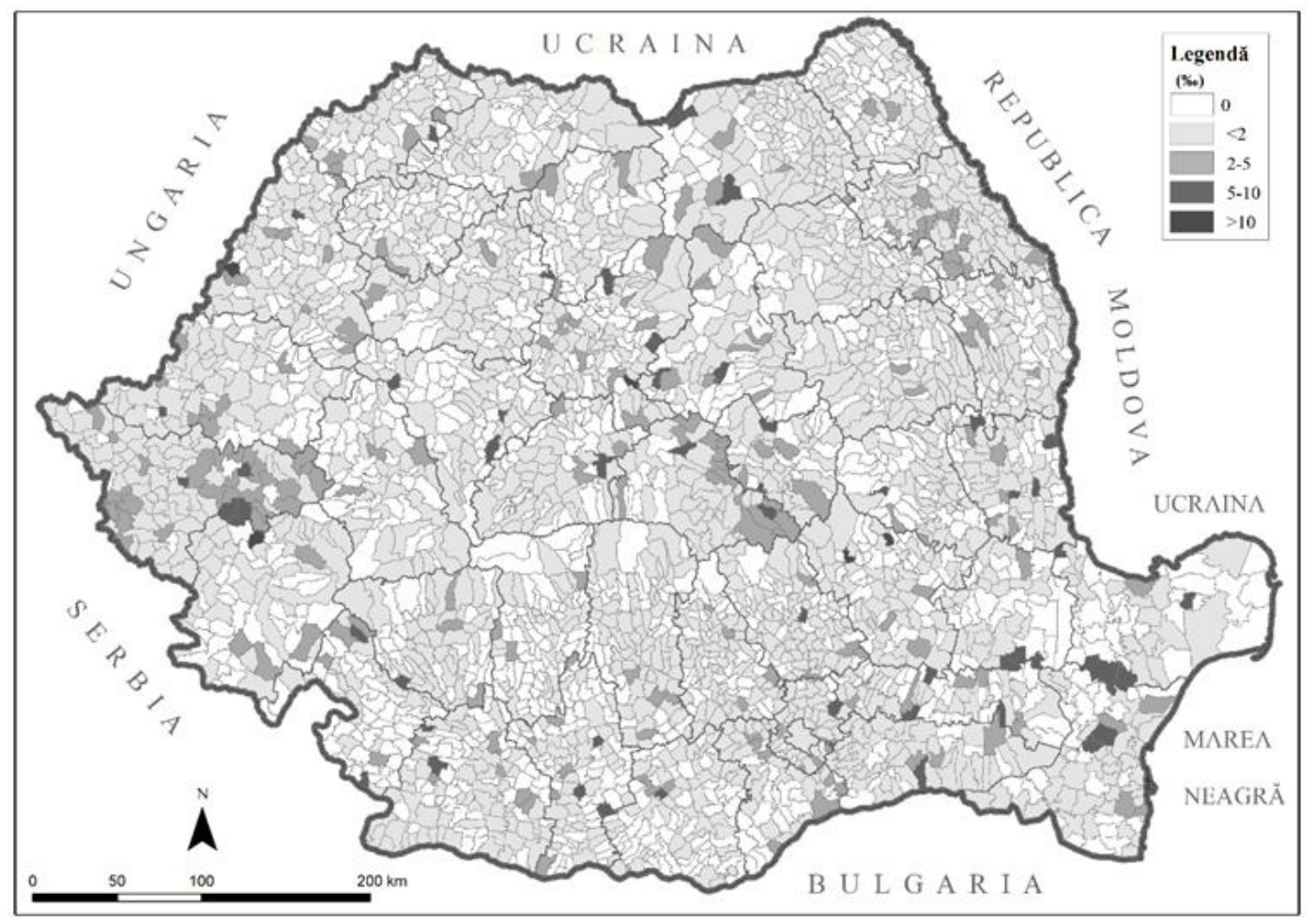

Figure 10. Geographical distribution of pediatric cancer -total (\%) year 2016. Source: Ministry of Health

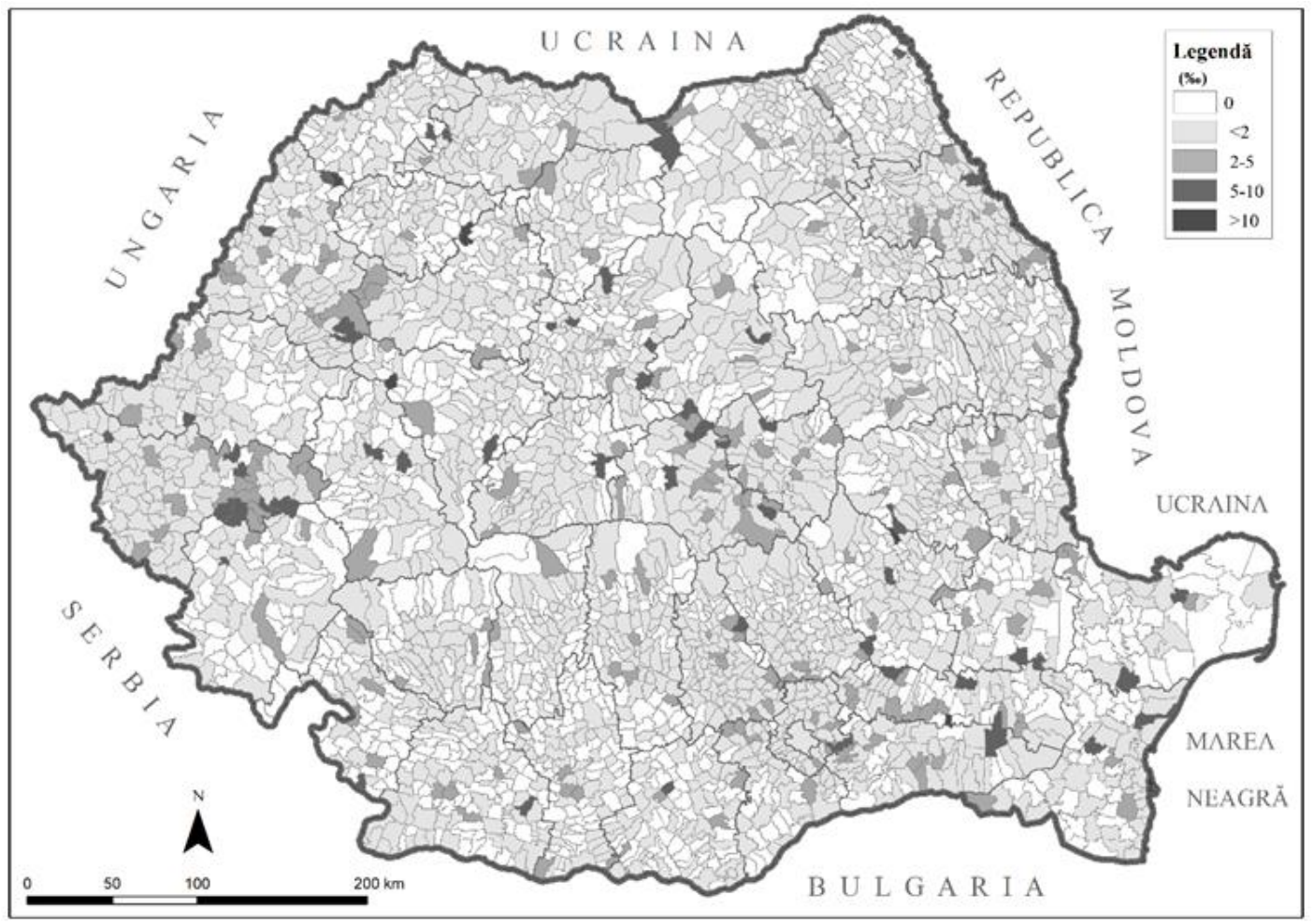

Figure 11. Geographical distribution of pediatric cancer -total (\%) year 2017. Source: Ministry of Health 


\section{CONCLUSIONS}

Analyzing the literature, we noticed that the lack of relevant data is a general problem, not having relevant data at a detailed level implies irrelevant results. For a better understanding of this phenomenon and making of public policy or to support the existing ones, it is necessary to know the space in which this phenomenon takes place, to know the geographical specificity of the areas with extreme values and to try to establish the common elements of these geographical areas. This study represents the first approach to the pediatric cancer situation in Romania from this point of view, which will be followed by a more detailed research. The extreme maximum values tend to be located near large industrial areas heavily polluted, especially during periods of maximum capacity.

\section{DISCUSSIONS}

As mentioned earlier, the survival rate for pediatric cancer has increased significantly since the 1990s worldwide due to advances in medicine, but has stagnated for various reasons, one of which is the discrepancy between countries' incomes, development and prioritization of medical system. In Romania, as well as in neighboring countries such as Bulgaria, Hungary, the Republic of Moldova (Eastern Europe), the survival rate of the young population is about $70 \%, 10$ percent less than Western Europe.

In order to be able to take measures in this directive, it is necessary to implement defining public policies to support those affected, and for this we need to know the incidence of existing cases and new cases, a first step is made by associations such as the association "Dăruiește Aripi" which wants to develop a National Register of Pediatric Oncology. [13], [14].

\section{REFERENCES}

[1] Childhood Cancer (epa.gov).

[2] https://www.cancer.gov/ An Analysis of the National Cancer Institute's Investment in Pediatric Cancer Research, National Cancer Institute, 2013.

[3] Julie A. Ross, Richard K. Severson, Leslie L. Robison, Brad H. Pollock, Joseph P. Neglia, William G. Woods, G. Denman Hammond, Pediatric cancer in the United States. A preliminary report of a collaborative study of the childrens cancer group and the pediatric oncology group, Cancer, vol. 71, pp 3415-3421, 1993.

[4] Michael E Scheurer, Philip J Lupo, Joachim Schüz, Logan G Spector, Joseph L Wiemels, Richard Aplenc, M Monica Gramatges, Joshua D Schiffman, Maria S Pombode-Oliveira, Jun J Yang, Julia E Heck, Catherine Metayer, Manuela A Orjuela-Grimm, Kira Bona, Paula Aristizabal, Mary T Austin, Karen R Rabin, Heidi V Russell, David G Poplack, An overview of disparities in childhood cancer: Report on the Inaugural Symposium on Childhood Cancer Health Disparities, Houston, Texas, 2016, Pediatric Hematology and Oncology, vol. 35, 2018.

[5] https://www.daruiestearipi.ro/

[6] CHILDREN WITH CANCER IN ROMANIA (hospitalteachers.eu)

[7] Julie A. Ross, Richard K. Severson, Brad H. Pollock, Leslie L. Robison, Childhood cancer in the united states: A geographical analysis of cases from the Pediatric Cooperative Clinical Trials Groups, Cancer vol. 77, pp 201-207, 1997.

[8] Juan A.Ortega-García, Fernando A.López-Hernández, AlbertoCárceles-Álvarez, José L.Fuster-Soler, Diana I.Sotomayor, Rebeca Ramis, Childhood cancer in small 
geographical areas and proximity to air-polluting industries, Environmental Research vol. 156, pp 63-73, 2017.

[9] Mark N. Fluchel, Anne C. Kirchhoff, Julia Bodson Carol Sweeney, Sandra L. Edwards, Qian Ding, Gregory J. Stoddard, Anita Y. Kinney, Geography and the burden of care in pediatric cancers, Pediatric Blood and Cancer, vol. 61, pp 1918-1924, 2014.

[10] David A Siegel, Jun Li, S Jane Henley, Reda J Wilson, Natasha Buchanan Lunsford, Eric Tai, Elizabeth A Van Dyne, Geographic Variation in Pediatric Cancer Incidence United States, 2003-2014, MMWR Morb Mortal Wkly, pp 707-713, 2018.

[11] David A. Siegel, Lisa C. Richardson, S. Jane Henley, Reda J. Wilson, Nicole F. Dowling, Hannah K. Weir, Eric W. Tai, Natasha Buchanan Lunsford, Pediatric cancer mortality and survival in the United States, 2001-2016, Cancer, vol 126, pp 4379-4389, 2020.

[12] Eva Steliarova-Foucher, Charles Stiller, Murielle Colombet, Peter Kaatsch, Roberto Zanetti, Rafael Peris-Bonet, Registration of childhood cancer: Moving towards panEuropean coverage? European Journal of Cancer, vol. 51, pp 1064-1079, 2015.

[13] https://ec.europa.eu/info/policies/public-health_en

[14] https://www.daruiestearipi.ro/registrul-national-al-cancerelor-la-copil/ 